Dog Whistle Mascots: Native American Mascots as Normative Expressions of Prejudice

\author{
Michael W. Kraus ${ }^{1}$, Xanni Brown ${ }^{1}$, and Hannah Swoboda ${ }^{2}$ \\ ${ }^{1}$ Yale University, ${ }^{2}$ Chicago, Illinois
}




\begin{abstract}
In this research we examine how normative expressions of prejudice shape university communities. Across four studies, we examine the prevalence of a former university mascot depicting harmful stereotypes about Native Americans and how exposure to that mascot influences people's attitudes and behaviors. In Study 1, images of the mascot persist on more than $10 \%$ of university apparel worn by students, in $50 \%$ of campus spaces, and in $5 \%$ of images searched online. Surveying students on this campus, we find that students with lower (higher) reported explicit prejudice also tended to have lower (higher) belonging at the university (Study 2). In two final experimental studies ( $N=683$ ), when compared to stereotype free university advertisements exposure to the stereotypic mascot reduced donations to the university by 5.5\%, and in particular, among people low versus high in explicit prejudice (Studies 3 and 4). Overall, these findings suggest that institutional norms play an important role in expressions of prejudice and experiences of belonging.
\end{abstract}




\section{Dog Whistle Mascots: Native American Mascots as Normative Expressions of Prejudice}

Stereotypic Native American mascots, those popularized by professional sports teams like the Cleveland Indians and the Chicago Blackhawks, have a significant and outsized influence on perceptions of American Indigenous peoples. Due to the history of erasure and genocide of these peoples, Americans writ large have few opportunities to experience Native American cultures and their communities in everyday life (Pewewardy, 1996; 1999). As such, stereotypic mascots have the capacity to reinforce harmful stereotypes of indigenous populations in ways that constrain the representation of these peoples in contemporary society, and relegate them as artifacts of the past (Black, 2002; Farnell, 2004; Fryberg, Markus, Oyserman, \& Stone, 2008). Thanks in large part to the persistent activism of Native Americans since at least the 1960s (Baca, 2004; Black, 2002; Society of Indian Psychologists, 1999), organizations, including the American Psychological Association, have gradually acknowledged that these mascots are expressions of prejudice against Native American peoples (APA, 2005). However, though it has been 13 years since the APA formally recognized the potential for harm of these mascots, invited more research into their consequences (e.g., Fryberg et al., 2008; Kim-Prieto et al., 2010; Freng \& Willis-Esqueda, 2011; LaRocque et al., 2011), and called for psychologists to take an active role in raising awareness, more work is necessary as many of these mascots persist at high schools, colleges, and on sports teams (Waldstein, 2018).

In particular, we observe that official organizational positions shape norms and customs surrounding intergroup attitudes (Asch, 1963; Tankard \& Paluck, 2016; Paluck \& Green, 2009). In the case of one public university in the Midwestern USA, the stereotypic mascot that we and others refer to as "the Chief" — a formulation created by a White undergraduate student in 1926 (King, 2004)—was officially removed from the university in 2007 in response to pressure from 
the National Collegiate Athletic Association (NCAA). And yet, despite this official removal the university continues to unofficially support the mascot's presence on campus, and has never replaced the mascot, sanctioned students or local businesses for continuing to use its likeness, or countered the powerful norms that associated the mascot with the university. Accordingly, visual representations of the Chief are still quite common on campus according to anecdotal accounts (see Figure 1; Lippert, 2018). These anecdotes highlight the need for a more rigorous analysis, and in the present research we sought to systematically understand how campus norms that encourage stereotypic Native American imagery on campus influence people's experiences with and attitudes toward the university. Although we focus our analysis on one Midwestern university, we have chosen to leave the name of the university out of this report because, although we cannot generalize to other contexts with these data, we raise the possibility that what happens with stereotypic Native American imagery in one community could happen in other communities. We refer to the specific Midwestern university under study here as the focal university from this point forward.

Figure 1. Pictures of the Chief photographed by the authors in 2015. The top left picture depicts a t-shirt purchased at a store adjacent to campus. The top right picture depicts an artist's rendering of the mascot at a local bar across the street from the university psychology department. The bottom left panel shows a decal on the car window of the next-door neighbor of the first author. The bottom right panel depicts the ostensible grave of the mascot on the front lawn of a house two blocks from campus. 

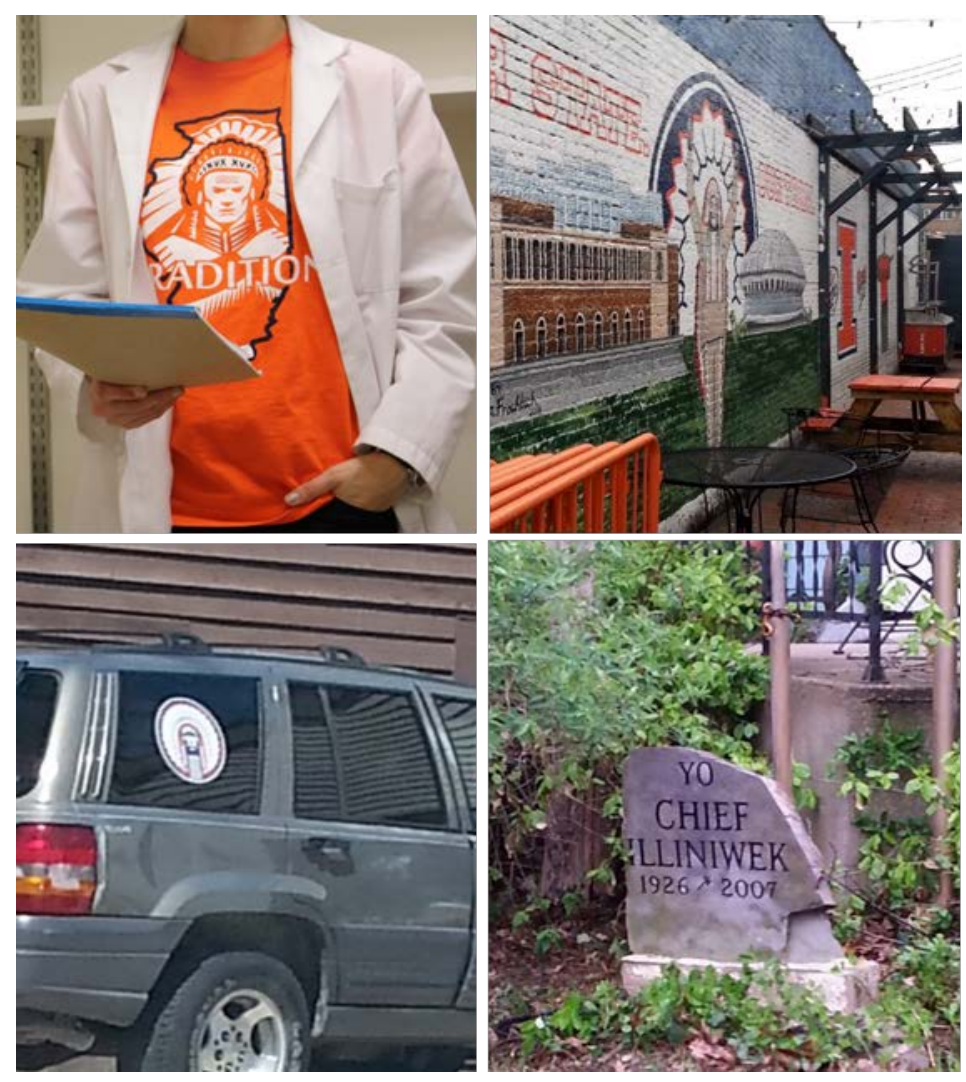

\section{Native American Stereotypes and Institutional Signaling}

Decades of research on social norms suggest that people tend to reference and understand norms through perceptions of individual behavior, summary information about groups, and institutional signals (Aarts \& Dijksterhuis, 2003; Asch, 1955; Bandura, 1971; Cialdini \& Goldstein, 2004; Gelfand \& Harrington, 2015; Gelfand, Harrington, \& Jackson, 2017; Tankard \& Paluck, 2016). Institutions can influence norms by sending signals about new norms or by incentivizing changes in norms (Packer, 2008; Pruckner \& Sausgruber, 2013; Tankard \& Paluck, 2015; Tyler \& Jackson, 2014). For instance, hotels that inform guests that most other hotel guests save water (by reusing towels) increase water conservation relative to a control message (Goldstein, Cialdini, \& Griskevicius, 2008; Schultz, Khazian, \& Zaleski, 2008). 
Norms are also critical in the realm of intergroup relations and expressions of prejudice. For instance, people report expressing prejudice toward out-groups at a magnitude that closely tracks the extent that norms allow for expressions of prejudice toward that group (Crandall, Eshleman, O'Brien, 2002). In recent work, blatant forms of dehumanization that include the explicit comparison of outgroups to less evolved hominids are positively associated with aggressive actions against those outgroups, a finding that suggests normative and blatant dehumanization has direct consequences for intergroup conflict (Kteily, Bruneau, Waytz, \& Cotterill, 2015; for a review, see Kteily \& Bruneau, 2017a).

Based on this analysis, the case of the Chief can be thought of as one institution's failure to clearly and effectively communicate changes in norms. Since the university officially removed the mascot, there have been few efforts made to separate the old mascot from the university at official sporting events (Ryan, 2018) or through the licensing and sale of official university apparel (e.g., gamedayspirit.com). Given this analysis of the institutional signaling of the mascot's permissibility on campus, we expected that stereotypic Native American images will be more prevalent, in both campus and online spaces at the focal university, where institutional signals are weak or nonexistent, then at comparison universities with no prior history of these stereotypic mascots (Study 1a), or at universities who have more effectively separated from the old stereotypic mascot by actually replacing it with an alternative (Study 1b).

\section{Native American Stereotypes as Normative Expressions of Prejudice}

Whereas the first study begins with an examination of the question of whether it is normative to see stereotypic Native American imagery on campus, the remaining studies examine how the observed prevalence of this imagery can impact attitudes toward the university. As expressions of prejudice, stereotypic Native American mascots have several adverse impacts 
on those students and community members who come in contact with the university. Despite descriptions of mascots like the Chief as representations of moral virtue (e.g., bravery, honor), these mascots dehumanize and erase modern Indigenous peoples by suggesting that Native Americans are an artifact of the past instead of present members of the university community (Black, 2002; Farnell, 2004; King, 2004; Leavitt, Covarrubias, Perez, \& Fryberg, 2015). Moreover, through the movement of mascot merchandise, stereotypic Native American mascots are another means by which universities profit off of the cultural products of Native Americans, while simultaneously downplaying the US government's past and current violent relationship with these sovereign nations (Black, 2002; Grounds, 2001).

Evidence suggests that these mascots also have a negative social impact on Native Americans: For instance, Fryberg and colleagues (2008) examined the impacts of exposure to stereotypic mascots on Native Americans, finding that exposure reduced state self-esteem, lowered perceptions of community worth, and reduced achievement-related future selves (e.g., Fryberg et al., 2008; also see Fryberg, Covarrubias, \& Burack, 2013; Leavitt, Covarrubias, Perez, \& Fryberg, 2015). Relative to White students, Native American students experience more negative affect after viewing a slideshow of images related to the University of North Dakota's “Fighting Sioux” mascot, regardless of whether this slideshow contained images rated as “neutral” or “controversial” (LaRocque et al., 2011). In related work, a lack of role models for Native American middle school students reduced school belonging relative to students with Native-American role models (Covarrubias \& Fryberg, 2015). It is for these reasons that some legal scholars suggest stereotypic Native American mascots violate a Native American student's capacity to experience full and equal use of university spaces (Baca, 2004). 
Theoretically, exposure to stereotypic mascots has several implications for social judgments of Native Americans by racial outgroups. Because racial categorization is based on cues, norms, and customs, university reliance on Native American stereotypes has direct consequences for how Indigenous peoples are perceived and represented in the minds of outgroups (Banks, Eberhardt, \& Ross, 2006; Kang \& Bodenhausen, 2015; Peery \& Bodenhausen, 2008). Notably, stereotypic Native American mascots are ahistorical—and as in the case of the Chief, not representative of a specific group of Native Americans (Farnell, 2004) — which serves to further obscure the reality of the violent past and current relationship between the US government and Indigenous peoples (Grounds, 2001). Additionally, experiments find positive associations between implicit negative attitudes about Native American mascots and Native American peoples (Chaney et al., 2011). Taken together, the above research indicates that the continued presence of stereotypic Native American mascots on university campuses has harmful psychological effects on Native American students and communities, as well as implications for how Native Americans are (mis)perceived by outgroups.

Based on the above analysis, we have chosen to characterize the appearance of stereotypic Native American mascots in campus spaces as expressions of prejudice because of the many adverse consequences of these mascots for Indigenous peoples. Notably, the characterization of these mascots as expressed prejudice is independent of the intents of the members of the campus community who bring the mascot to campus for a variety of reasons that include mundane processes such as strict adherence to prevailing campus social norms as well as explicit intentions to harm Native American peoples (Bonilla-Silva, 2006).

In the present research, conceptualizing the presence of stereotypic Native American mascots as normative expressions of prejudice has direct implications for campus climate. As a 
ubiquitous and public expression of prejudice, mascots like the Chief communicate to the campus community that expressing prejudice is commonplace in campus spaces. Because norms are a powerful deterrent for expressed prejudice (e.g., Crandall et al., 2002; Ktiely et al., 2015; Richeson \& Sommers, 2016), the unchallenged expression of Native American stereotypes can shift norms and thereby increase prejudice (Kteily \& Bruneau, 2017a). As one example, a study from Kim-Prieto and colleagues (2010) finds that exposure to Native American mascots increases stereotyping of Asian Americans. Similarly, as norms of political discourse have increasingly welcomed overt expression of racism these trends have coincided with an uptick in racially motivated hate crimes in America (Fbi.gov, 2017). As well, recent research finds that normative expressions of dehumanization against Muslims and Mexican immigrants during the 2016 Presidential election cycle increased support for aggressive policies against these groups of people (Kteily \& Bruneau, 2017b). Given this analysis we expect that the presence of stereotypic Native American mascots will serve as a normative message that people who endorse and express prejudice are more welcome on campus relative to those that do not.

The above analysis leads to our central hypothesis: Given that norms favor controlling expressions of prejudice (Crandall et al., 2002; Devine, 1989), we predict that exposure to stereotypic Native American mascots will reduce belonging and engagement with the university in general. Moreover, we expect this pattern to be particularly strong among people low (versus high) in explicit racial prejudice toward Native Americans. We tested this prediction in two ways: First, by examining student engagement with campus spaces in a correlational study (Study 2); and second, by examining donations and belonging when the university was, versus was not, accompanied by normative expressions of Native American stereotypes (Studies 3 and 4). This central hypothesis suggests that the prevalence of stereotypic Native American mascots 
is causal in increasing belonging in and engagement with the university, particularly among people high in explicit prejudice toward Native Americans.

\section{Study 1: The Prevalence of Native American Stereotypes on Campus and Online}

In Study 1 our goal was to examine the prevalence of Native American imagery on campus. To that end, we investigated the prevalence of stereotypic Native American imagery depicting the Chief in communal space on the focal university campus. We expected that institutional signals of the mascot's permissibility that we outlined in the introduction would allow the Chief to proliferate throughout public campus spaces and in online search results relevant to the university. As a comparison set for Study 1a, we collected similar data on the prevalence of stereotypic Native American imagery on two other university campuses with no recent history of stereotypic Native American mascots. Our Study 1b comparison set for online spaces involved online search results for four universities that had removed their stereotypic Native American mascot at the same time as the focal university, but had communicated clear institutional signals by replacing the mascot with an alternative. All studies were approved by the institutional review boards of the University of Illinois and Yale University.

\section{Method}

\section{Study 1a: Campus Apparel}

Participants were 1,506 young people observed across three university campuses in the United States. Of the total sample, 1,000 students were observed on the focal university campus in 12 unique locations. Of these campus participants, 57.9\% appeared to be White (as judged by the observer) and $42.1 \%$ appeared to belong to a racial minority group. For comparison, White students make up $43.44 \%$ of students on the focal university campus (Office of Inclusion and Intercultural Relations, 2017). We focused our analysis on participants who appeared to be of the 
typical age of college students and we excluded from analyses participants whose cold-weather outerwear completely obscured their clothing underneath. The twelve focal university campus locations were chosen because they are highly trafficked and representative of a diverse range of students: We observed students in buildings with large lecture halls, library reading rooms and quiet study spaces, the main student quadrangle, two of the on-campus gymnasiums, the student union building, and at an end-of-season NCAA basketball game. All data were collected between the spring and fall of 2015 on the focal university campus. The size of the sample was chosen based on a desire to collect enough data to detect even a small effect of $D=0.20$ and to sample people from a variety of campus spaces in sufficient numbers. We eventually settled on a desired sample of 1,000 participants from the focal university and 500 from the comparison campus, which would provide us with more than $99 \%$ statistical power to find this small effect. We did not analyze data for this or our subsequent studies until all data were collected. All materials, manipulations, and measures are reported in this manuscript.

One coder recorded their observations in a survey of each campus space by unobtrusively observing the clothing of students as they exercised, studied, talked, or walked. The coder determined if a student was wearing university apparel, if that apparel had images of or references to the stereotypic Native American mascot, and whether that individual was a visible member of a racial minority group. A second coder, blind to study hypotheses, overlapped on 100 cases of the coded observations to establish reliability. There was $100 \%$ agreement between the two coders on these 100 cases on all coded dimensions.

We used a similar methodology to collect observational data on two other university campuses, one public Western university and one private Eastern university, both in 2016. These campuses were chosen out of convenience, because both institutions are peers of the focal 
university, and because the school mascots did not employ Native American stereotypes either formally or informally. A total of eight campus locations were examined across the two campuses resulting in the observation of an additional 506 participants in this comparison set. For these observations we only collected data on the presence or absence of images of or references to Native American stereotypes.

\section{Study 1b: Online Search}

For Study 1b we examined the first 100 images returned from three internet image searches relevant to campus athletics for the focal university and four additional comparison universities — chosen because they had all changed their mascots from a Native American stereotype to an alternative (e.g., the Red Wolf) at the same time that the Chief was removed. The three comparison search terms were “[University Name] Athletics,” “[University Name] Football,” and “[University Name] Basketball.” A total of 1,500 images were coded for this analysis as including stereotypic Native American imagery or messages or not by the second author and by one additional coder blind to study hypotheses. These two coders reached agreement on $100 \%$ of coded images. All image searches were conducted in January of 2019 using a google images search with private results disabled. All data for Studies 1a and $1 \mathrm{~b}$ are available online (https://osf.io/zbu3x/). We chose a target sample size of greater than 600 images based on our interest in detecting a minimal effect size of $D=.20$. A sample of 600 gives us more than $99 \%$ power to detect an effect size of this minimum size.

\section{Results}

\section{Study 1a: Campus Apparel}


Across the 1,000 participants at the focal university with the informal stereotypic Native American mascot, 323 of those students were wearing apparel with University imagery and 34 of those students were wearing images depicting Native American stereotypes_-making these stereotypes visible on $3.4 \%$ of all clothing, $10.5 \%$ of all university apparel, and in $50 \%$ of the twelve campus locations where observations took place. Of the 34 students wearing Native American stereotypes, 24 (70.5\%) were White as categorized by our coders. In comparison, none of the 506 students observed at two comparison universities without these mascots wore apparel depicting Native American stereotypes across the eight locations where observations took place (see Figure 2).

Figure 2. The first three categories depict results from Study 1a, showing the prevalence of stereotypic Native American images on apparel worn in campus spaces at the focal university with the informal stereotypic Native American mascot versus two comparison universities as a function of all apparel, university affiliated apparel, and number of campus spaces observed. The last category shows the results from Study $1 \mathrm{~b}$ comparing image searches between the focal university and the four comparison universities that had replaced their stereotypic Native American mascots with an alternative. 


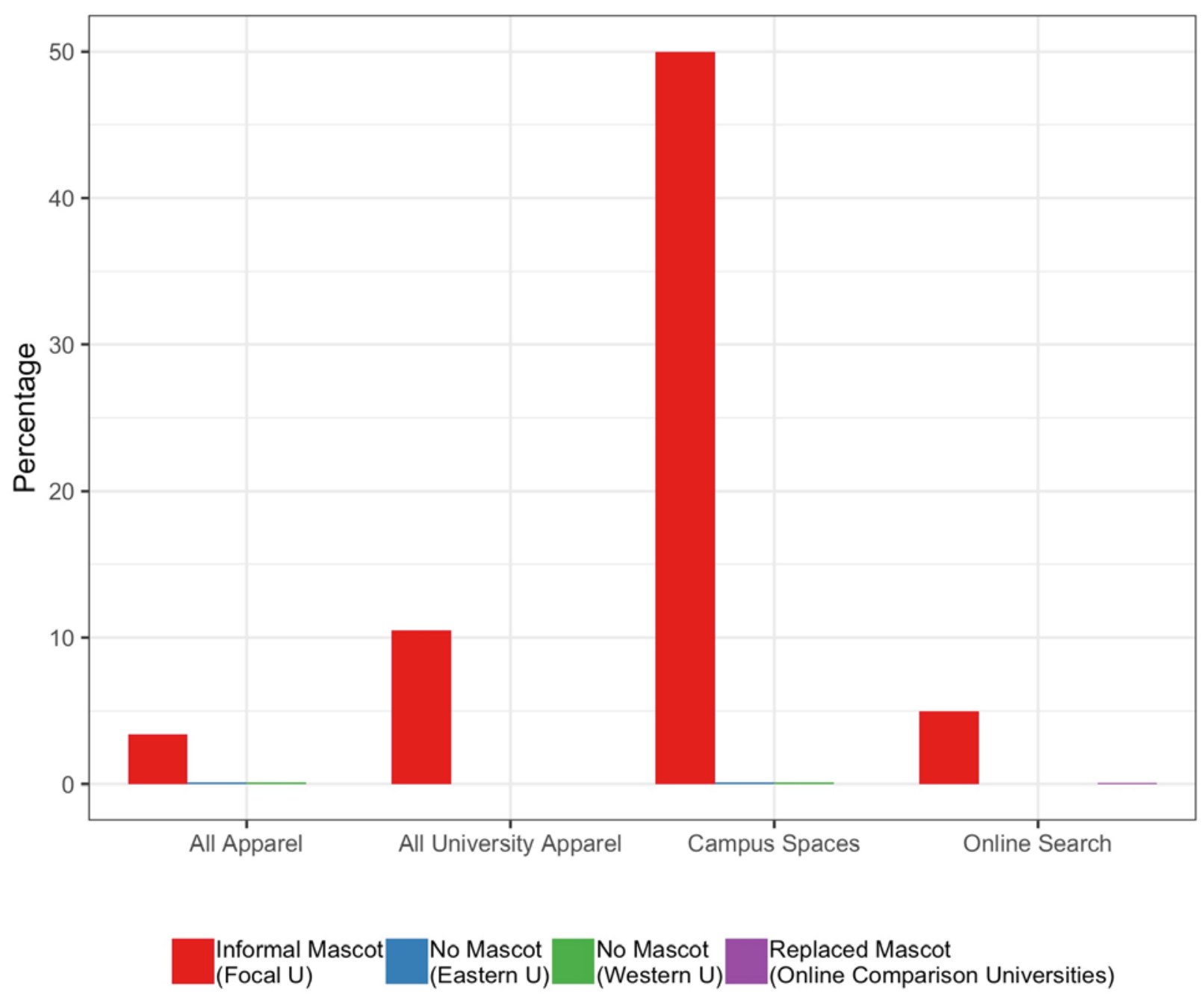

We compared the prevalence of Native American stereotypes at the focal university to the lack of presence of Native American stereotypes on the comparison campuses using a chisquare $2 \mathrm{X} 2$ contingency analysis with Yates continuity correction. This analysis is a test of independence that allows us to draw inferences about whether the distribution of stereotypic Native American imagery at the focal university deviated significantly from the distribution at the comparison campuses. When confining our analysis to those wearing university apparel, the distribution at the focal university showed a significantly higher prevalence of stereotypic Native 
American imagery than did the comparison campuses $X^{2}(1)=52.90, p<.001$. An analysis across all apparel also showed significantly more Native American imagery at the focal university than the comparison campuses $X^{2}(1)=18.11, p<.001$. Comparing the 12 focal university campus spaces to the 8 comparison spaces showed a similar pattern. Though the small number of locations $(n=20)$ does not lend itself to a reliable contingency analysis, stereotypic Native American imagery was present in 50\% of campus spaces studied at the focal university, compared to $0 \%$ of comparison university spaces. Taken together, these results validate our expectations that stereotypic Native American imagery was more prevalent on the clothing and in the campus spaces at the focal university than at the comparison campuses.

\section{Study 1b: Online Search}

We conducted a similar Yates-corrected chi-square analysis with a 2 X 2 contingency table for online search results collapsed across the three search terms for the focal university and our four comparison universities that had replaced their stereotypic Native American mascot (see Figure 2). Consistent with our expectations, 15 of the 300 images (5.0\%) in the focal university search contained stereotypic Native American imagery whereas only 6 of the 1,200 images (0.5\%) for the comparison universities returned these stereotypic images $X^{2}(1)=32.02, p<.001$. These results indicate that institutional signals communicated by replacing the comparison university stereotypic mascots was associated with reduced prevalence of the mascot on university image searches relative to the focal university, where similar institutional signals were absent.

\section{Discussion}

In these first two studies we have established that stereotypic Native American imagery is present on one university campus. In half of the locations where observations took place, on 10\% 
of all university apparel, in more than 5\% of online search images, and 3.4\% of all apparel, images of Native American stereotypes were visible on campus or online. These results validate our initial expectation that a lack of institutional signaling is associated with a higher visibility of Native Americans stereotypes. Though we did take steps to compare the prevalence of stereotypic imagery on the focal university campus to other schools with similar academic standards and histories with similar mascots, these studies are correlational and so causal associations cannot be drawn from these data. Given that the prevalence of norms is typically assessed using the examination of public behavior (Aarts \& Dijksterhuis, 2003; Gelfand et al., 2017), Study 1 provides some initial behavioral evidence indicating that seeing Native American stereotypes is normative on the focal university campus.

\section{Study 2: Student Attitudes about the Chief on Campus}

In Study 1 we examined the presence of stereotypic Native American imagery on campus and online but a weakness of that prior work was that we did not have an opportunity to ask students about their attitudes toward campus and toward Native American stereotypes. Study 2 offered a unique opportunity to collect impressions and reactions from focal university students themselves. In particular, we sought to test our central hypothesis, that the presence of stereotypic Native American imagery is an example of the normative expression of prejudice, and as such exposure to these norms would be associated with stronger linkage between prejudice against Native Americans and self-reports of belonging on campus. In Study 2, we asked students about their implicit and explicit prejudice towards Native Americans along with their attitudes about the Chief and their belonging on campus. We expected that students lower (higher) in explicit prejudice would report less (more) belonging on campus.

\section{Method}




\section{Participants and Procedure}

Study 2 participants were 201 Midwestern university students (113 women, 87 men, 1 gender non-binary) who signed up to participate in the study through the psychology department volunteer and paid subject pools. All participants self-described their racial identity in the following ways: 85 White, 72 Asian American, 26 Latinx, 8 Black, 3 Native Americans, and 7 as mixed or other racial categories. Participants were awarded one course credit or $\$ 5$ for participation. All study data are posted online (https://osf.io/zbu3x/).

The original study was designed to subtly expose participants to images of the Chief versus images of the focal university logo through a t-shirt worn surreptitiously by the experimenter. However, two post-hoc realizations led us to question this methodology. First, our analyses from Study 1 suggests that the Chief is in more than half of all campus spaces surveyed and on $10 \%$ of all university related apparel. These observations make exposure to stereotypic Native American imagery commonplace and normative on campus and our subtle manipulation weak in retrospect. Second, there was good evidence in the manipulation check data that more than half of participants (51.7\%) did not notice the clothing worn by our experimenter. For these reasons we lost confidence in our original experimental design. Critically, no differences on any measure reported here emerge as a function of the clothing manipulation and all analyses remain unchanged when controlling for the experimental manipulation. Sample size for the study was determined based on our intention to detect an effect size of $D=0.40$ between the two experimental conditions with $80 \%$ power, an effect size of the average published study in social psychology (Richard, Bond, \& Stokes-Zoota, 2003).

\section{Measures}


Explicit prejudice. To measure explicit prejudice toward Native Americans we used the Political and Racial Attitudes Toward Native Americans scale (PRATNA), which measures explicit negative attitudes and opinions about Indigenous peoples (Brantmeier, 2012). The scale includes 21 items (e.g. "It is now unnecessary for the U.S. government to honor their treaty obligations to Native tribes”) and participants respond using 7-point Likert scales (1= disagree strongly, 7 = agree strongly). The PRATNA showed high internal consistency $(M=2.82 ; S D=$ $0.84 ; \alpha=0.91)$. We also used the modern racism scale to examine explicit reports of prejudice toward Black Americans (e.g. "Blacks are getting too demanding in their push for equal rights”) to see if belonging on campus is associated with explicit prejudice to non-Native American racial groups (McConahay, 1986). The modern racism scale used the same 7-point Likert scales (1 = disagree strongly, $7=$ agree strongly $)$ and exhibited high internal consistency $(M=2.51 ; S D=$ $1.16 ; \alpha=0.87)$

Belonging on campus and attitudes toward the mascot. Based on scales used in prior research (Walton \& Cohen, 2011; Dasgupta \& Dennehy, 2017) we assessed belonging and engagement at the focal university with 11 items assessing engagement with activities at the university (e.g. "I feel a sense of belonging when I am with other Midwestern university students." "I attend sporting events at the university” "I identify with the university." "I show school spirit regularly”). The items employed the same 7-point agreement based Likert scales. The 11 items showed high internal consistency and thus we created an overall composite indicating mean belonging $(M=4.83, S D=1.02, \alpha=0.83)$.

We used seven items assessing attitudes toward the mascot (e.g. "I wish that the Chief was still the university's mascot”) and six items about positive or negative affect when seeing the mascot (e.g. "When I see images of the Chief on campus I feel happy/joyful”). Both scales used 
the same 7-point agreement based Likert scales. Because all these items showed high internal consistency and results did not differ between scales, we collapsed across all these items to form an overall mean for mascot attitudes $(M=4.44, \mathrm{SD}=1.37 ; \alpha=.95)$.

Implicit Bias. We also examined more subtle and unintended bias against Native Americans using an Implicit Association Task (IAT). The Native American-White IAT was run on Inquisit and downloaded from project implicit (https://osf.io/tmbsf/). This implicit association task measures automatic associations between good and bad words and Native Americans and Whites. We used the scoring procedures outlined in prior research (Greenwald, Nosek, \& Banaji, 2003): Participants’ composite IAT scores were converted to a standard effect size D where higher scores indicate more pro-White and anti-Native American implicit bias $(M=0.27, S D=$ 0.43).

Demographic characteristics. In addition to assessing race and gender we asked participants if they had immediate members of their family who were focal university alumni $(-1$ = no, 1 = yes), 53 participants responded “yes” to this question. We also asked if participants had contact with Native Americans using two items (i.e., "I have known Native American people personally.” and “I come in contact with Native Americans on campus.”) with the same 7-point agreement based Likert scales $(M=3.11, S D=1.67 \alpha=.71)$. We also assessed social and economic liberal political ideology with two items that used 7-point Likert scales $(1=$ very conservative, $7=$ very liberal; $M=4.27, S D=1.11$ ).

\section{Results}

For our central hypothesis, we predicted that normative expressions of prejudice, such as the continued presence of the stereotypic Native American mascot on the focal university campus, are associated with lower (higher) belonging particularly among those low (high) in 
explicit prejudice. Thus we predicted, for Study 2, that lower ratings of prejudice would be associated with reports of reduced campus belonging among students, as well as more negative attitudes toward the mascot. We conducted a correlational analysis as an initial test of this prediction both with and without controlling for participants who reported family alumni status (see Table 1).

Across both correlational analyses lower self-reports of explicit prejudice toward Native Americans were associated with less belonging at the focal university and more negative attitudes toward the mascot. Lower scores on the modern racism scale were associated with more negatives attitudes toward the mascot but not less university belonging. Native American IAT scores showed a similar pattern—-lower pro-White bias was associated with less university belonging and more negative attitudes toward the mascot. Finally, more liberal students felt they belonged less at the university, exhibited significantly less explicit and implicit racial bias, and had less positive attitudes toward the mascot.

Table 1. Correlations between belonging on campus, measures of explicit and implicit (IAT) prejudice, attitudes toward the mascot, contact with Native Americans (NA), political ideology, and immediate family alumni status. Correlations below the diagonal are raw correlations whereas correlations above the diagonal are partial correlations controlling for family alumni status. Asterisks indicate that $\mathrm{p}<.05$.

\begin{tabular}{llllllll}
\hline & Belong & NA Prejudice & $\begin{array}{l}\text { Modern } \\
\text { Race }\end{array}$ & IAT & $\begin{array}{l}\text { Mascot } \\
\text { Attitudes }\end{array}$ & Contact & Liberal \\
\hline Belong & - & $.17^{*}$ & .13 & $.19 *$ & $.49 *$ & $.18^{*}$ & $-.17^{*}$ \\
NA Prejudice & $.16^{*}$ & - & $.73^{*}$ & $.32^{*}$ & $.46^{*}$ & -.06 & $-.36^{*}$ \\
Modern Race & .12 & $.73^{*}$ & $\ldots$ & $.25 *$ & $.41^{*}$ & .01 & $-.35^{*}$
\end{tabular}




\begin{tabular}{llllllll} 
IAT & $.20^{*}$ & $.30^{*}$ & $.24 *$ & - & $.22 *$ & .02 & -.14 \\
Mascot & $.50^{*}$ & $.43^{*}$ & $.38^{*}$ & $.24^{*}$ & - & .03 & $-.24^{*}$ \\
Attitudes & & & & & & & \\
Contact & $.17^{*}$ & -.06 & .02 & .01 & .03 & - & .06 \\
Liberal & $-.19^{*}$ & $-.33^{*}$ & $-.34^{*}$ & $-.15^{*}$ & $-.26^{*}$ & .06 & - \\
Alum & .14 & -.11 & -.09 & .09 & $.20^{*}$ & -.02 & $-.14^{*}$ \\
\hline
\end{tabular}

To assess the robustness of these associations we sought to examine the relationship between self-reports of implicit and explicit prejudice and belonging at the university while controlling for student race (dummy coded with White as the comparison and Asian, Latinx, and another racial group as the race categories) ${ }^{1}$, liberal ideology, focal university alumni status of family members, and prior contact with Native Americans given that the correlational analysis shows that contact was associated with greater university belonging. For this analysis, all predictors were standardized in this study and the subsequent studies. The analysis of explicit prejudice against Native Americans revealed an association of explicit prejudice that was consistent with our predictions: Lower (higher) explicit Native American prejudice was associated with lower (higher) university belonging $B=.17, t(193)=2.33, p=.021$. In the model, Asian Americans $B=-.35, t(193)=-4.60, p<.001$, Latinx participants $B=-.26$, $t(193)=$ -3.69, $p<.001$, and other race participants $B=-.22, t(193)=-3.16, p=.002$ reported less belonging relative to White students. As well, alumni status was not associated with belonging $B$ $=-.01, t(193)=-0.16, p=.874$, and greater liberal ideology was associated with less belonging $B$ $=-.14, t(193)=-1.99, p=.048$. This effect of ideology is interesting given data suggesting that college campuses, on average, are seen as more welcoming of liberal versus conservative 
students (Pew Research Center, 2017). Unexpectedly, contact with Native Americans was associated with greater belonging $B=.18, t(193)=2.82, p=.005$. We are cautious in interpreting this unexpected association, but one possible explanation is that given the low numbers for enrollment of Native Americans on the focal university campus (i.e., 0.05\%, Office of Inclusion and Intercultural Relations, 2017) it could be the case that students view contact with the Chief mascot as contact with Native Americans.

For the parallel analysis examining attitudes toward the Chief a similar but more robust pattern of results emerged: Lower (higher) explicit Native American prejudice was associated with more negative (positive) attitudes toward the Chief, $B=.43, t(193)=6.39, p<.001-$ importantly this association was effectively double that of university belonging. In the model, Asian Americans $B=-.22, t(193)=-3.02, p=.003$, Latinx participants $B=-.19, t(193)=-2.93, p$ $=.004$, and other race participants $B=-.19, t(193)=-2.94, p=.004$ reported less positive attitudes toward the Chief relative to White students. In addition, alumni status was significantly positively associated with positive attitudes toward the chief $B=.13, t(193)=1.98, p=.0495$, a finding suggesting that prior family exposure to the university was associated with more positive Chief attitudes. For our remaining predictor variables, contact with Native Americans $B=.06$, $t(193)=1.01, p=.311$, and liberal ideology were not associated with positive Chief attitudes $B=$ $-.10, t(193)=-1.51, p=.134$.

We conducted similar analyses using modern racism and pro-White IAT scores as predictors in place of explicit prejudice against Native Americans. In general, the results using these scales to predict belonging and Chief attitudes were similar, but less robust. For belonging, in addition to the same pattern of associations for the control variables, neither modern racism $B$ $=.11, t(193)=1.46, p=.146$, nor IAT pro-White bias $B=.12, t(193)=1.72, p=.087$ were associated 
with university belonging. For Chief attitudes both lower modern racism $B=.37, t(193)=5.41, p<$ .001 , and less IAT pro-White bias $B=.14, t(193)=2.00, p=.046$ were associated with more negative attitudes toward the Chief. Importantly, these IAT pro-White bias associations with negative Chief attitudes emerged after adjusting for race, suggesting that even among non-White students, higher pro-White implicit bias was associated with more positive attitudes toward the Chief.

\section{Discussion}

Study 2 provides some initial correlational evidence from students at the focal university that aligns with our central hypothesis: In particular, those with lower (higher) levels of explicit prejudice toward Native Americans reported lower (higher) belonging at our focal university and less (more) positive attitudes toward the Chief. Additionally, White students reported greater feelings of belonging and more positive attitudes toward the mascot than did Asian American, Latinx, or other race students, a finding consistent with some of the observational data on wearing stereotypic Native American imagery from Study 1. Though the overall observed pattern of effects is consistent with our predictions and moves beyond our initial observational study by assessing the direct experiences of students on campus, the correlational nature of the data nevertheless limits our capacity to make causal claims about the impact of Native American stereotypes on campus on people’s engagement with and belonging at the university. Studies 3 and 4 were designed as two experiments to directly test this causal prediction.

\section{Studies 3 and 4: Giving in the Context of Stereotypic Native American Mascots}

Up to this point we have provided some initial evidence that stereotypic Native American mascots are present and normative on one focal university campus and are associated with lower (higher) belonging among students who report low (high) explicit prejudice toward Native 
Americans. In our final two experiments we sought to determine if exposure to stereotypic Native American mascots is causal in reducing charitable giving to universities in general, if people low (high) in explicit prejudice toward Native Americans are particularly likely to reduce (increase) their giving when exposed to these stereotypes, and if exposure to these stereotypes reduces (increases) belonging among those low (high) in prejudice.

\section{Methods}

\section{Participants}

The methods for Studies 3 and 4 are similar and as such we describe the participants and procedures in aggregate. Participants were recruited for a large-scale survey online through MTurk (Study 3) or Qualtrics Panels (Study 4) as part of a survey examining perceptions and evaluations of university advertisements. Participants in Study 3 were adults from the USA. A total of 301 participants were recruited for the experiment including 239 White, 26 Black, 12 Latinx, and 24 who reported another or multiple racial categories. In Study 4, a total of 582 participants were recruited if they were current residents of the state where the focal university is located and in numbers that reflect state census demographic characteristics for race. Participants identified with the following racial categories for Study 4: 348 White, 91 Black, 105 Latinx, and 35 who reported another or multiple racial categories. We recruited Study 4 from the same state as the focal university because these participants are more likely to be potential donors to the focal university.

Sample size for Study 3 was based on powering the study sufficiently $(N=296)$ to detect a main effect difference on donation behavior to the focal university between experimental and control groups of a $D=0.40$ with $90 \%$ power. For Study 4 , the sample size was determined after finding a between group donation difference of $D=0.31$ in Study 3. We then powered Study 4 to 
have at least $95 \%$ power to detect this same size effect $(N=440)$. No analyses took place before collection of the full samples for both Studies 3 and 4 . All study materials and data for both experiments are publically available online (https://osf.io/zbu3x/). For Study 4, the condition main effect prediction — that exposure to Native American stereotypes would decrease donations was pre-registered prior to data collection, as was our secondary analysis of the interaction between stereotype exposure and explicit prejudice toward Native Americans on donations (https://osf.io/b9u4d/). That latter pre-registered analysis differs from the analysis we report in the main text in that the main text analysis controls for participant race and political ideology. Results were the same with or without these control variables (see supplementary analyses).

\section{Procedure}

When participants accessed the survey they first received instructions about the purpose of the 10-15 minute study. In Study 3, participants learned that in this specific survey the researchers were interested in their impressions of specific college and university campuses based on descriptions and photographs taken from the university advertising materials. In the control condition, participants read a description of the focal university and three other universities of the same state and viewed pictures of those universities that depict students in university spaces and campus buildings. In the stereotype exposure condition, participants read the same descriptions of the focal university and three other universities in the same state but in this case the student pictures on campus were intermixed with a handful of images showing students wearing stereotypic Native American clothing and apparel, consistent with the norms observed in Study 1. The comparison university materials remained the same for the stereotype exposure and control conditions. 
In Study 4, participants were first pre-selected based on their state of current residence. Next participants learned that in this specific survey the researchers were interested in their impressions of college and university campuses based on descriptions and photographs taken from the university advertising materials. Participants were then randomly assigned to the same two experimental conditions. In the control condition, participants read a description of the focal university and viewed pictures that depict students in university spaces and campus buildings. In the stereotype exposure condition, participants read the same description of the focal university but in this case the student pictures on campus were intermixed with a handful of images showing students wearing stereotypic Native American clothing and apparel, again consistent with the norms observed in Study 1. Study 4 methods differ from Study 3 in that the advertising materials are only shown for the focal university and not for the comparison universities.

Next, in both studies participants are given $\$ 2.00$ to be used specifically as a donation to the universities that they just learned about through advertisements. Participants must decide how to allocate the $\$ 2.00$ between the four universities by using four sliding scales for each university that range from 0 to 200 cents $\left(M_{\text {Study } 3}=51.02, S D_{S t u d y 3}=30.44 ; M_{S t u d y 4}=78.81\right.$, $\left.S D_{S t u d y 4}=60.66\right)$. Participants were required to donate the full amount but could divide up the donation to each of the four universities, our focal university inclusive. ${ }^{2}$

In Study 4, participants also had a chance to rate their belonging at the focal university as they were receiving information about the university and campus-as a means to better understand and explore the psychological mechanisms underlying their donation behavior. Participants rated their overall belonging at the focal university on three items at three time points as they were learning about the campus—one time point prior to the experimental manipulation of exposure to Native American stereotypes, and two time points during and 
directly following exposure. The items were "I have a positive impression of the university.”, "I feel I belong at the university.”, and "I identify with students at the university." Participants answered these questions on 100 point feeling thermometers and responses showed high internal consistency across all three time points $\left(M_{\text {Time1 }}=63.59, S D_{\text {Time1 }}=25.56, a_{\text {Time1 }}=.86 ; M_{\text {Time2 }}=\right.$ 63.13, $\left.S D_{\text {Time2 }}=24.55, a_{\text {Time2 }}=.86 ; M_{\text {Time3 }}=62.03, S D_{\text {Time3 }}=23.20, a_{\text {Time3 }}=.88\right)$.

After reporting their donation decisions in both Studies participants filled out scores on the PRATNA $\left(M_{S t u d y 3}=2.20, S D_{S t u d y 3}=0.79 ; M_{S t u d y 4}=2.41, S D_{S t u d y 4}=0.72\right)$. For Studies 3 and 4 we used a 5-point agreement based Likert scale for the PRATNA. Political ideology was assessed as in Study $2\left(M_{S t u d y 3}=3.46, S D_{S t u d y 3}=1.86 ; M_{S t u d y 4}=3.85, S D_{S t u d y 4}=1.72\right)$ using 7point Likert scales. Participants ended the experiment by answering questions about the study hypothesis, completing a manipulation check assessing the extent they were aware of the clothing in the images, and were fully debriefed about the study purpose. Following the collection of all data, donations in the amount specified by participants were delivered to each of the four universities.

\section{Results}

\section{Presentation of Results}

Both Studies 3 and 4 utilized similar experimental manipulations and donation outcomes. Because of this similarity in measures and methods, we present results of the individual studies in parallel followed by a mini meta-analysis across both experiments (Goh, Hall, \& Rosenthal, 2016).

\section{Manipulation Check}

We first assessed the effectiveness of our manipulation with a single item question at the end of the experiment asking participants if any of the students were wearing clothing associated 
with Native Americans. A chi-square test of independence found that indeed, participants in the stereotype exposure condition were significantly more likely to answer "Yes" to this question than control condition participants in both studies $X_{\text {Study3 }}^{2}(1)=95.11, p_{\text {Study } 3}<.001 ; X_{\text {Study } 4}^{2}(1)=$ 213.28, $p_{\text {Study } 4}<.001$. Together these results indicate that the conditions differentially exposed participants to Native American stereotypes.

\section{University Donations}

We first sought to determine if exposure to Native American stereotypes on campus advertisements would decrease donations to the university in general. For both experiments we conducted an independent samples t-test between the control and stereotype exposure groups on amount donated to the focal university. The results are displayed in Figure 3. In both studies participants in the control condition donated more than in the experimental condition, however this difference only reached conventional statistical significance in Study $3, t_{\text {Study3 }}(299)=-2.70$,

$p_{\text {Study3 }}=.007, d_{\text {Study } 3}=.31 ; t_{\text {Study } 4}(580)=1.15, p_{\text {Study } 4}=.252, d_{\text {Study } 4}=.09$. Examined in aggregate across the two studies, we find that exposure to Native American stereotypes significantly reduced donations $Z_{\text {Combined }}=2.44, p_{\text {Combined }}=.015, d_{\text {Combined }}=.16$, CI95\% [.03 to .30]. In practical terms, across our studies the focal university experienced a total funding deficit of $\$ 33.50$ as a result of exposing potential donors to Native American stereotypes.

Figure 3. The left panel shows mean differences in donation in cents provided by participants when exposed to Native American stereotypes versus control images of the focal university. The right panel shows the total amount donated to the focal university in the stereotype exposure versus control conditions across both studies. 

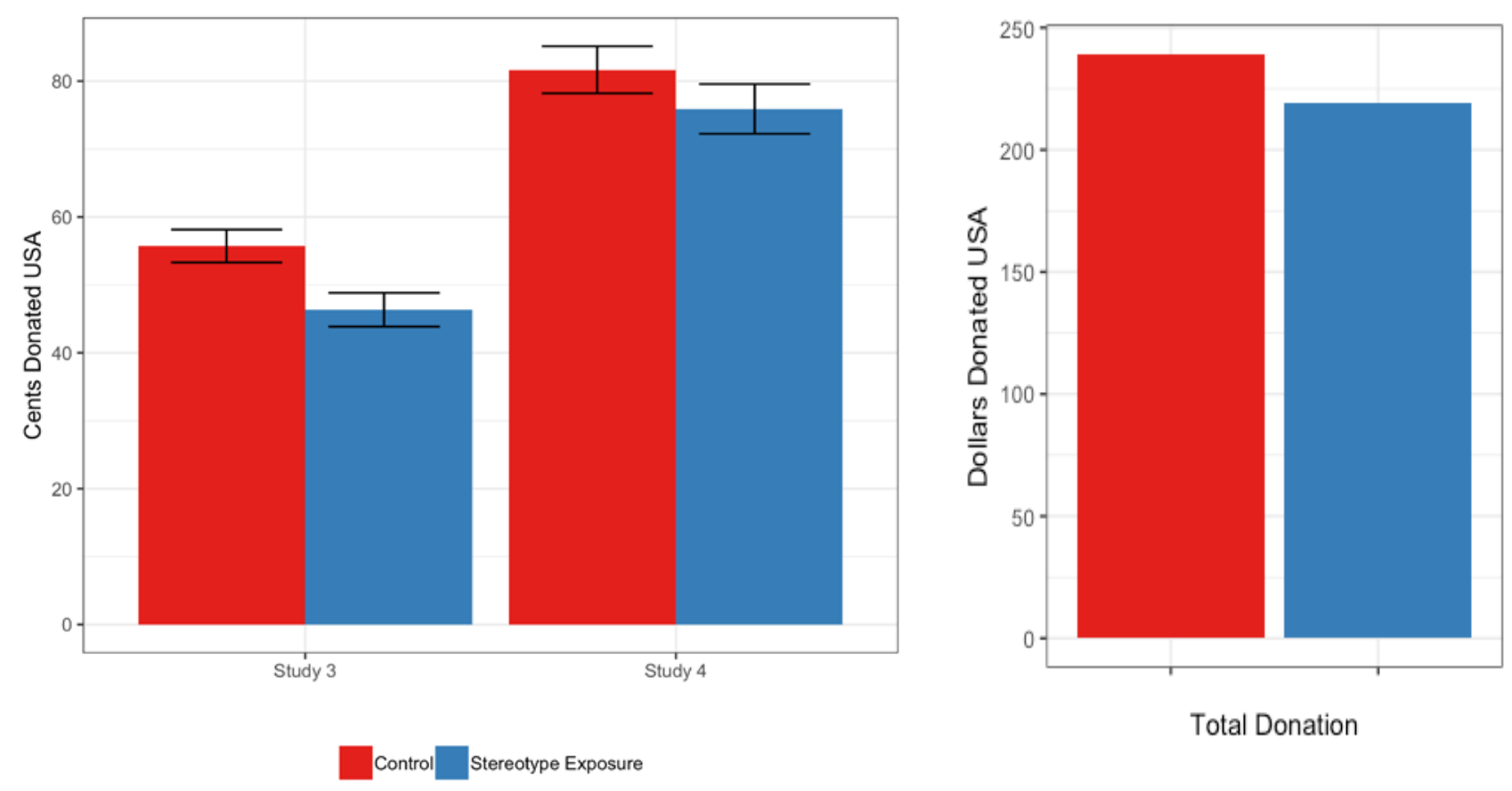

We also predicted that when exposed to Native American stereotypes, people low (high) in explicit prejudice would donate less (more) to the focal university. To test this hypothesis we first conducted a regression analysis in both studies where we predicted donations to the focal university with condition (coded “1” for stereotype exposure, and “-1” for control), dummy coded race (with Black, Latinx, and other race categories with White as the comparison group), political ideology, explicit prejudice against Native Americans measured with the PRATNA, and the interaction between condition and explicit prejudice. In Study 3, the analysis yielded a significant main effect of stereotype exposure $B_{\text {Study } 3}=-.16, t_{\text {Study } 4}(293)=-2.77, p_{S t u d y 3}=.006$, a nonsignificant effect of explicit prejudice $B_{S t u d y 3}=.08$, $t_{\text {Study3 }}(293)=1.25, p_{S t u d y 3}=.212$, and a nonsignificant interaction $B_{S t u d y 3}=.11, t_{\text {Study3 }}(293)=1.92, p_{\text {Study3 }}=.056$. None of the race effects were significant in Study $3 t_{S t u d y 3}<1.00$. As well, conservative ideology was not associated with donations $B_{\text {Study3 }}=.03$, $t_{\text {Study3 }}(293)=0.52, p_{\text {Study } 3}=.607$. 
In Study 4, the analysis yielded a nonsignificant main effect of stereotype exposure $B_{S t u d y} 4$ $=-.04, t_{\text {Study } 4}(517)=-1.05, p_{S t u d y} 4=.296$, a nonsignificant effect of explicit prejudice $B_{S t u d y} 4=-$ $.003, t_{\text {Study } 4}(517)=-.072, p_{\text {Study } 4}=.942$, and a significant interaction between explicit prejudice and stereotype exposure $B_{S t u d y 4}=.13, t_{S t u d y 4}(517)=3.09, p_{S t u d y 4}=.002$. In Study 4, Black $B_{\text {Study } 4}$ $=-.09, t_{\text {Study } 4}(517)=-2.04, p_{\text {Study } 4}=.042$, Latinx $B_{\text {Study } 4}=-.14, t_{\text {Study } 4}(517)=-3.12, p_{\text {Study } 4}=.002$, but not other race participants $B_{S t u d y 4}=-.01, t_{\text {Study } 4}(517)=-0.01, p_{S t u d y 4}=.730$ were less likely to donate than White participants—a finding consistent with the race effects observed in Studies 1 and 2. Conservative ideology was positively associated with greater donations $B_{S t u d y 4}=.14$, $t_{\text {Study } 4}$ $(517)=2.95, p_{\text {Study } 4}=.003$.

To probe the overall interaction effect across our two studies we examined correlations between explicit prejudice and donations within each experimental condition. This analysis, aggregated across Studies 3 and 4, shows a pattern consistent with our hypothesis: In both studies explicit prejudice was uncorrelated with donations in the control condition $\left(r_{S t u d y 3}=-.01\right.$, $\left.p_{\text {Study } 3}=.881 r_{\text {Study } 4}=-.04, p_{\text {Study } 4}=.539\right)$ but was significantly positively correlated with donations in the stereotype exposure condition $\left(r_{\text {Study } 3}=.20, p_{S t u d y 3}=.012 ; r_{S t u d y 4}=.16, p_{S t u d y 4}=\right.$ .005). Examining the effect size across the studies yields no correlation in the control condition $R_{\text {Combined }}=-.03, Z_{\text {Combined }}=-0.56, p_{\text {Combined }}=.575, C 195 \%$ [-.12 to .07] and a significant positive correlation in the stereotype exposure condition $R_{\text {Combined }}=.17, Z_{\text {Combined }}=3.66, p_{\text {Combined }}<.001$, CI95\% [.08 to .26]. Critically, the association in the stereotype exposure condition between explicit prejudice and donations was larger in magnitude than the same association in the control condition, as indicated by the non-overlapping confidence intervals. Overall then we find that those lower (higher) in explicit prejudice gave less (more) to the university when exposed to 
Native American stereotypes, whereas explicit prejudice did not predict donations in the control condition where university images did not include these stereotypes.

\section{Native American Stereotypes and University Belonging}

To explore if Native American stereotype exposure reduced feelings of belonging on campus we conducted an exploratory analysis in Study 4 where we compared condition differences to reports of belonging at the three time points while participants learned about the focal university as a function of their levels of explicit Native American prejudice. We conducted this analysis using an Analysis of Variance where belonging at the three time points was the within subjects factor, explicit prejudice was a continuous predictor, and stereotype exposure was the between subjects factor. The analysis yielded a nonsignificant effect of belonging $F(2,1042)=2.50, p=.083$, a significant interaction between belonging and stereotype exposure $F(2,1042)=11.71, p<.001$, a significant interaction between belonging and explicit prejudice $F(2,1042)=11.86, p<.001$, and a significant three-way interaction $F(2,1042)=14.24$, $p<.001$. The three-way interaction was further clarified by a significant linear contrast $F(1,521)$ $=18.02, p<.001$. This linear three-way interaction is shown in Figure 4 as scatterplots of the association between standardized explicit Native American prejudice and belonging as a function of stereotype exposure condition. As the figure shows, at time 1 prior to actual stereotype exposure, both the stereotype exposure $r(289)=.05, p=.391$, and control $r(293)=-.07, p=.267$ conditions show nonsignificant associations between explicit prejudice and belonging. However, following Native American stereotype exposure this association begins to diverge such that those that report lower (higher) explicit prejudice come to report lower (higher) university belonging at both time $2, r(289)=.16, p=.006$ and time $3, r(289)=.26, p<.001$. In contrast, the control condition continued to show no association between explicit prejudice and belonging at time 2, 
$r(293)=-.04, p=.475$ and time $3, r(293)=-.06, p=.312$. As well, the magnitude of the correlation was significantly lower in the control condition versus the stereotype exposure condition at both time $2, Z=2.42, p=.016$, and time $3, Z=3.91, p<.001$.

Figure 4. Associations between standardized Native American prejudice and belonging at three time points as a function of stereotype exposure (in red) and control (in blue) conditions where Time 1 belonging reports are collected prior to exposure to Native American stereotypes in the exposure condition and Times 2 and 3 are during and immediately after exposure to these stereotypes.

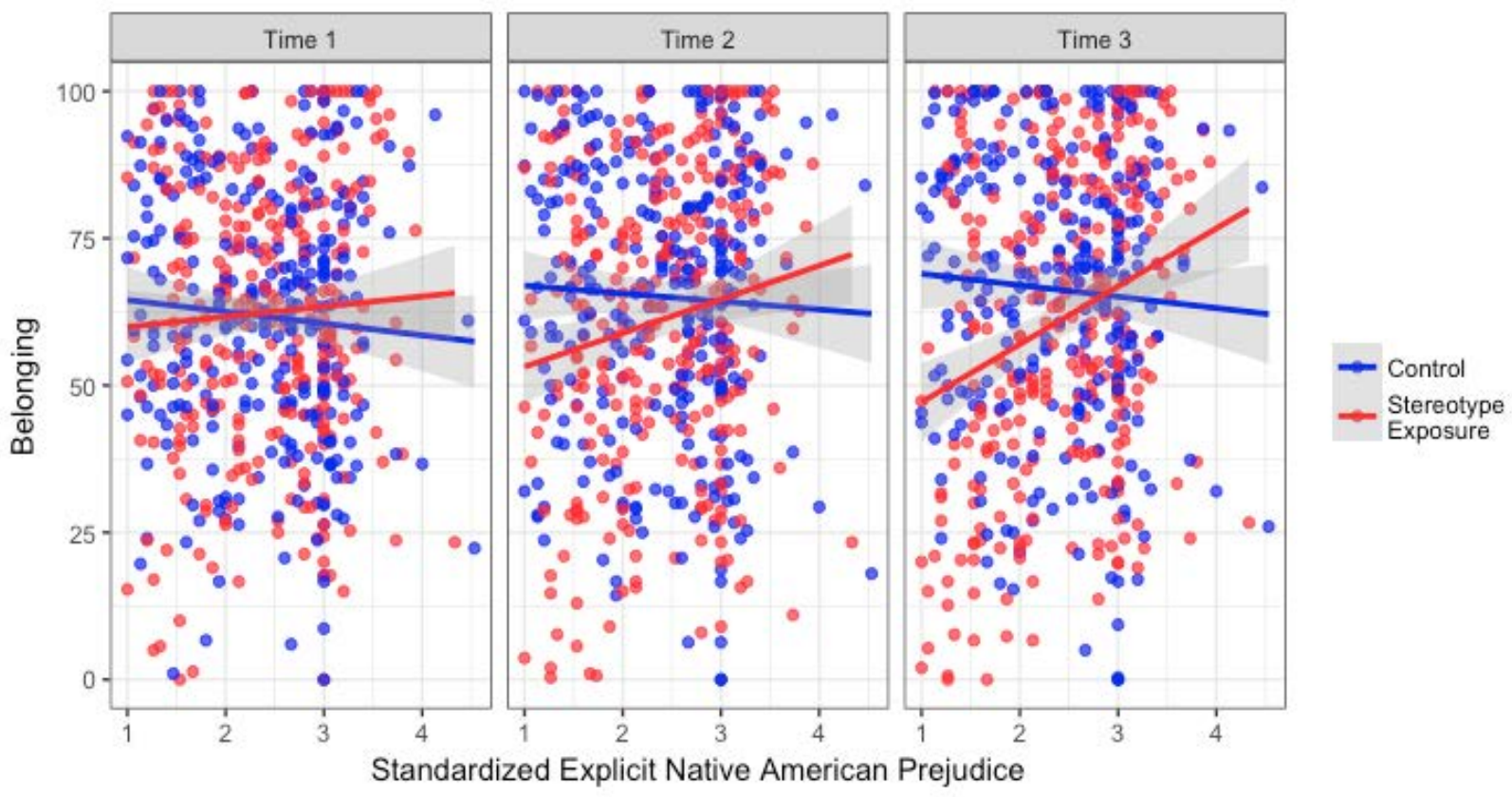

Although mediation analyses are a relatively poor proxy for testing the causal process for how exposure to Native American stereotypes influences donations through feelings of belonging (e.g., Smith, 2012), we were able to conduct this preliminary mediation analysis predicting donation behavior in Study 4. In this analysis (Hayes, 2012), amount donated was our 
dependent variable, condition was our independent variable and post-exposure belonging averaged across time 2 and 3 was our mediator. In the model, stereotype exposure did not predict donations $b=-1.20, t(579)=-0.50, p=.619$, but it did predict belonging $b=-2.30, t(580)=-$ 2.30, $p=.022$. Belonging, the mediator, was a significant predictor of donations $b=0.73, t(579)$ $=7.32, p<.001$. Moreover, the analysis yielded a significant indirect effect of Native American stereotype exposure on donations through belonging $b=-1.68$, CI 95\% [-3.26, -0.22$]$. Overall, this mediation analysis provides some preliminary support for the prediction that exposure to Native American stereotypes reduces donations to the university because it reduces belonging.

\section{Discussion}

Taken together, the results of two experiments support our hypothesis that exposure to Native American stereotypes reduces donation behavior. In these studies, stereotype exposure reduced donations by a magnitude of $5.5 \%$ of the total amount donated to our focal university relative to no exposure. We also found that donation behavior was particularly susceptible to stereotype exposure as a function of explicit prejudice against Native Americans. For those low (high) in explicit prejudice, Native American stereotype exposure elicited smaller (larger) donations, whereas no association was found in the control condition.

Follow-up analyses provide clues about the psychological mechanisms surrounding these patterns of donation behavior. Specifically, whereas our experimental conditions did not differ in reports of university belonging prior to stereotype exposure, following exposure to Native American stereotypes, participants high in explicit prejudice tended to report more belonging at the university whereas those low in explicit prejudice reported less belonging. Again, no systematic association with explicit prejudice and belonging emerged when Native American stereotypes were not shown along with university advertisements. Together, this analysis 
indicates that exposure to Native American stereotypes in university advertisements both reduced donations to the focal university and self-reports of belonging at that university, particularly for those low versus high in explicit prejudice.

\section{General Discussion}

Public institutions have an important and often overlooked role in shaping norms surrounding prejudice in society—both in terms of their formal practices and in terms of their communicated institutional norms (Kteily \& Bruneau, 2017a; Tankard \& Paluck, 2016). In this regard, how an institution chooses to address or ignore expressions of racism communicated by its members has far reaching implications for its membership going forward (López, 2014). In this collection of studies we have used one test case, institutional norms surrounding one former university mascot, to examine how institutional signals surrounding the expression of prejudice impact belonging within that institution. Across four studies we found that a lack of institutional signaling that a stereotypic Native American mascot is inappropriate on campus has allowed the normative expression of that stereotype to continue on campus and online, specifically in $50 \%$ of institutional spaces and on more than $10 \%$ of all visible institution-related apparel. In addition, we found support for our central hypothesis: Exposure to these norms, where stereotypic Native American imagery is present on campus, elicits reduced engagement and university belonging, in particular, among those low versus high in explicit prejudice. Importantly, Native American stereotypic imagery, relative to university advertisements devoid of these images, reduced actual donations to the institution by 5.5\%, and was particularly likely to decrease (increase) donations among those low (high) in prejudice.

It is important to reflect for a moment on what it might be like for students of color, and specifically Native American students, on a university campus where 10\% of university apparel 
and 50\% of university spaces contain harmful stereotypes of Indigenous peoples (e.g., Fryberg et al., 2008). How might student belonging and space usage be impacted by this hostile university climate? What barriers to increasing diversity and inclusion are erected by allowing these stereotypes to persist so visibly on campus and within community spaces? A direct hypothesis derived from this work is relevant to the mental health and well-being of students of color living within the institution. Specifically, we predict that continued exposure to these harmful stereotypes elicits greater weathering, allostatic load, and other negative health outcomes relative to campuses without these stereotypes (Geronimus, Hicken, Keene, \& Bound, 2006). Another prediction derived directly from this work is that campus spaces with stereotypic mascots or other racist imagery might become increasingly segregated along racial lines over time (e.g., Alexander, 2012; Desmond, 2016; Massey \& Denton, 1993; Shedd, 2015).

Dwelling for a moment on the finding that university advertisements including Native American stereotypes reduced overall donations by 5.5\%, one line of future research might examine the community costs of normative expressions of prejudice. Based on these data it is possible that these normative expressions attract a certain type of donor and student to the university that reflects demographic and personal characteristics that are associated with heightened explicit prejudice and reduced diversity (López, 2014). How these institutions are likely to fare in a country that is increasingly becoming more ethnically diverse (Craig \& Richeson, 2014a; 2014b), and has been relatively less tolerant of racial prejudice over time (at least up until very recently), is an important topic of future research (Bialick \& Cillufo, 2016). These trends have clear implications for the maintenance of inequality in society-as higher education institutions are one means by which individuals ascend the socioeconomic hierarchy (e.g., Harackiewicz et al., 2016; Kraus, Park, \& Tan, 2017; Piff, Kraus, \& Keltner, 2018). That 
normative expressions of prejudice hamper a university's capacity to recruit a more diverse student body might also damage the capacity of the university to serve communities of color that would benefit the most from expanded educational opportunities featuring more welcoming university cultures (Shedd, 2015). Future research would benefit from a consideration of these areas of future inquiry.

Notwithstanding the promise of the current findings, a few important limitations bear mentioning. The most direct limitation of the present work is its total focus on one institution with the assumption that this case will generalize to other institutions and organizations. We hypothesize that any institution that communicates norms that allow for expressions of prejudice will attract people who are higher in prejudice, but despite this prediction there are likely important moderators to this phenomenon. One might be timing, as this particular focal university has not formally intervened to replace their mascot in over a decade, and as such some of what we observe in these samples might reflect the sheer amount of time where these associations with prejudice at the focal university have been allowed to crystallize (Jost, 2006; Jost, Banaji, \& Nosek, 1994). Another moderator might be the type of institution, as it is possible that a state institution of higher education is presumably expected to welcome more diverse students with egalitarian views than other for-profit institutions (e.g., Bhattacharjee, Dana, \& Baron, 2017). In a less egalitarian institution, normative expressions of prejudice may not impact belonging to the same magnitude. Systematic examinations of normative expressions of prejudice across industries and firms are warranted. It is also notable that, though we measure public behavior as a proxy for norms, we did not specifically measure perceptions of campus social norms surrounding the mascot. Studies that do these measurements could help us better understand some of the reasons why students report wearing the mascot, the extent that students 
feel social pressures in their clothing choices, and campus norms surrounding expressions of prejudice.

Although we examined the causal role of normative expressions of prejudice on belonging and donations at one focal university, our first two studies are correlational and should be interpreted as such. Understanding the bidirectional relations between prejudice and belonging is a topic worthy of further consideration, particularly regarding the potential role of third variables in these studies. For instance, it is possible that in the present studies people who are high in explicit prejudice are attracted to the focal university for other reasons independent of institutional signals of prejudice—-for the athletics or the prestige of the program or because of geographic constraints—and it is this attraction that allows the mascot to endure in campus spaces. Although some of our analyses here and in the supplementary materials that control for alumni status account, in part, for these alternatives, future research would benefit from a more rigorous examination of these explanations. It is also possible that the focal university has, with great effort, attempted to communicate institutional signals of greater egalitarianism, and these signals have simply been less well received due to the demographic characteristics of students and alumni—-thereby leaving the impression of inaction on the part of the mascot. Further examination of the types of institutional signals that are likely to be most effective in combatting prejudice is an important direction for future research—particularly given the power of blatant norms of dehumanization for shaping aggression against outgroups (Kteily \& Bruneau, 2017a). With that in mind, perhaps a definitive action to replace the mascot, as our online comparison universities did, is the appropriate course of action likely to be most effective in reducing the presence of normative prejudice on campus. Other actions to separate official campus events and 
licensed university apparel from the prior mascot are potential complimentary institutional actions to reduce the presence of normative prejudice on campus.

The present results highlight the important causal role that institutions play in shaping belonging and engagement on campuses through the communication of campus norms. Given rising racially motivated hate crimes in America (fbi.gov, 2017) as well as the recent proliferation of regressive social policies that blatantly discriminate against racial minorities (e.g., the border fence), perhaps there is no better time in recent history for both public and private institutions to play a more active role in the shaping of intergroup attitudes. Such actions, at least according to these data, have direct implications for both monetary outcomes of the institutions as well as who engages with and belongs within them. 


\section{Footnotes}

${ }^{1}$ The race coding of participants differed between Study 2 and Studies 3 and 4 due to subgroup sample size constraints. We did not wish to estimate effects for racial groups with $\mathrm{N}<$ 10 individuals, and as such the dummy coding of racial categories shifts from using Latinx, Asian American, and another race categories in Study 2 to using Black, Latinx, and another race categories in Studies 3 and 4. Importantly, when we examine race as a binary including with Whites coded as " 1 ” and non-Whites coded as “-1" we find similar effects across studies as with the dummy coding analyses (see supplementary analyses).

${ }^{2}$ Mean donations to the focal university were smaller in Study 3 than in Study 4 across experimental conditions. We believe this large difference arose because Study 3 provided participants with advertisements for all four universities whereas Study 4 only provided information about the focal university of interest. 


\section{Author Note}

The authors wish to acknowledge all past and current efforts conducted by Indigenous peoples and campus communities to challenge the legitimacy of the presence of Native American mascots on campuses across the country. The authors would also like to thank the micro organizational behavior group at Yale University for comments on an earlier version of this manuscript. 


\section{References}

Aarts, H., \& Dijksterhuis, A. (2003). The silence of the library: environment, situational norm, and social behavior. Journal of personality and social psychology, 84(1), 18.

Alexander, M. (2012). The new Jim Crow: Mass incarceration in the age of colorblindness. The New Press.

Asch, S. E. (1955). Opinions and social pressure. Scientific American, 193(5), 31-35.

Baca, L. R. (2004). Native images in schools and the racially hostile environment. Journal of Sport and Social Issues, 28(1), 71-78.

Bandura, A. (1971). Vicarious and self-reinforcement processes. The nature of reinforcement, 228278.

Banks, R. R., Eberhardt, J. L., \& Ross, L. (2006). Discrimination and implicit bias in a racially unequal society. California Law Review, 94(4), 1169-1190.

Bhattacharjee, A., Dana, J., \& Baron, J. (2017). Anti-profit beliefs: How people neglect the societal benefits of profit. Journal of personality and social psychology, 113(5), 671.

Bialick, K., \& Cilluffo, A. (2017). Six facts about black Americans for Black History Month. Pew Research Center. Retrieved from: http://www.pewresearch.org/fact$\underline{\text { tank/2017/02/22/6-facts-about-black-americans-for-black-history-month/ }}$

Black, J. E. (2002). The" mascotting" of Native America: Construction, commodity, and assimilation. The American Indian Quarterly, 26(4), 605-622.

Bonilla-Silva, E. (2006). Racism without racists: Color-blind racism and the persistence of racial inequality in the United States. Rowman \& Littlefield Publishers. 
Brantmeier, N. K. (2012). Undergraduate college student's attitudes toward Native Americans and their Native studies course experiences: A critical mixed methods study (Doctoral dissertation, Colorado State University).

Cialdini, R. B., \& Goldstein, N. J. (2004). Social influence: Compliance and conformity. Annu. Rev. Psychol., 55, 591-621.

Covarrubias, R., \& Fryberg, S. A. (2015). The impact of self-relevant representations on school belonging for Native American students. Cultural Diversity and Ethnic Minority Psychology, 21(1), 10.

Craig, M. A., \& Richeson, J. A. (2014a). More diverse yet less tolerant? How the increasingly diverse racial landscape affects White Americans’ racial attitudes. Personality and Social Psychology Bulletin, 40(6), 750-761.

Craig, M. A., \& Richeson, J. A. (2014b). On the precipice of a “majority-minority” America: Perceived status threat from the racial demographic shift affects White Americans’ political ideology. Psychological Science, 25(6), 1189-1197.

Crandall, C. S., Eshleman, A., \& O'brien, L. (2002). Social norms and the expression and suppression of prejudice: the struggle for internalization. Journal of personality and social psychology, 82(3), 359.

Dennehy, T. C., \& Dasgupta, N. (2017). Female peer mentors early in college increase women’s positive academic experiences and retention in engineering. Proceedings of the National Academy of Sciences, 114(23), 5964-5969.

Desmond, M. (2016). Evicted: Poverty and profit in the American city. Broadway Books. 
Devine, P. G. (1989). Stereotypes and prejudice: Their automatic and controlled components. Journal of personality and social psychology, 56(1), 5.

Farnell, B. (2004). The fancy dance of racializing discourse. Journal of Sport and Social Issues, 28(1), 30-55.

FBI hate crime reporting statistics (2017). Retrieved from: https://ucr.fbi.gov/hate-crime

Fryberg, S. A., Covarrubias, R., \& Burack, J. A. (2013). Cultural models of education and academic performance for Native American and European American students. School Psychology International, 34(4), 439-452.

Fryberg, S. A., Markus, H. R., Oyserman, D., \& Stone, J. M. (2008). Of warrior chiefs and Indian princesses: The psychological consequences of American Indian mascots. Basic and Applied Social Psychology, 30(3), 208-218.

Gelfand, M. J., \& Harrington, J. R. (2015). The motivational force of descriptive norms: For whom and when are descriptive norms most predictive of behavior?. Journal of CrossCultural Psychology, 46(10), 1273-1278.

Gelfand, M. J., Harrington, J. R., \& Jackson, J. C. (2017). The strength of social norms across human groups. Perspectives on Psychological Science, 12(5), 800-809.

Geronimus, A. T., Hicken, M., Keene, D., \& Bound, J. (2006). “Weathering” and age patterns of allostatic load scores among blacks and whites in the United States. American journal of public health, 96(5), 826-833. 
Goh, J. X., Hall, J. A., \& Rosenthal, R. (2016). Mini meta-analysis of your own studies: Some arguments on why and a primer on how. Social and Personality Psychology Compass, 10(10), 535-549.

Goldstein, N. J., Cialdini, R. B., \& Griskevicius, V. (2008). A room with a viewpoint: Using social norms to motivate environmental conservation in hotels. Journal of consumer Research, 35(3), 472-482.

Greenwald, A. G., Nosek, B. A., \& Banaji, M. R. (2003). Understanding and using the implicit association test: I. An improved scoring algorithm. Journal of personality and social psychology, 85(2), 197.

Grounds, R. A. (2001). Tallahassee, Osceola, and the hermeneutics of American placenames. Journal of the American Academy of Religion, 69(2), 287-322.

Harackiewicz, J. M., Canning, E. A., Tibbetts, Y., Giffen, C. J., Blair, S. S., Rouse, D. I., \& Hyde, J. S. (2014). Closing the social class achievement gap for first-generation students in undergraduate biology. Journal of educational psychology, 106(2), 375.

Hayes, A. F. (2012). PROCESS: A versatile computational tool for observed variable mediation, moderation, and conditional process modeling.

Jost, J. T. (2006). The end of the end of ideology. American psychologist, 61(7), 651.

Jost, J. T., Banaji, M. R., \& Nosek, B. A. (2004). A decade of system justification theory: Accumulated evidence of conscious and unconscious bolstering of the status quo. Political psychology, 25(6), 881-919. 
Kang, S. K., \& Bodenhausen, G. V. (2015). Multiple identities in social perception and interaction: Challenges and opportunities. Annual review of psychology, 66, 547-574.

King, C. R. (2004). This is not an Indian: Situating claims about Indianness in sporting worlds. Journal of Sport and Social Issues, 28(1), 3-10.

Kraus, M. W., Park, J. W., \& Tan, J. J. (2017). Signs of social class: The experience of economic inequality in everyday life. Perspectives on Psychological Science, 12(3), 422-435.

Kteily, N. S., \& Bruneau, E. (2017b). Darker demons of our nature: The need to (re) focus attention on blatant forms of dehumanization. Current Directions in Psychological Science, 26(6), 487-494.

Kteily, N., \& Bruneau, E. (2017a). Backlash: The politics and real-world consequences of minority group dehumanization. Personality and Social Psychology Bulletin, 43(1), 87104.

Kteily, N., Bruneau, E., Waytz, A., \& Cotterill, S. (2015). The ascent of man: Theoretical and empirical evidence for blatant dehumanization. Journal of personality and social psychology, 109(5), 901.

Leavitt, P. A., Covarrubias, R., Perez, Y. A., \& Fryberg, S. A. (2015). “Frozen in Time”: The Impact of Native American Media Representations on Identity and SelfUnderstanding. Journal of Social Issues, 71(1), 39-53.

Lippert, C. (January 29, 2018). ISG calls for removal of Chief symbols in University Buildings. Daily Illini. https://dailyillini.com/news/2018/01/29/isg-calls-removal-chief-symbolsuniversity-buildings/ 
López, I. H. (2015). Dog whistle politics: How coded racial appeals have reinvented racism and wrecked the middle class. Oxford University Press.

Massey, D. S., \& Denton, N. A. (1993). American apartheid: Segregation and the making of the underclass. Harvard University Press.

McConahay, J. B. (1986). Modern racism, ambivalence, and the modern racism scale.

Office of Inclusion and Intercultural Relations (February, 2017). Focal university student enrollment. Retrieved from: https://oiir.illinois.edu/about/demographics

Packer, D. J. (2008). Identifying systematic disobedience in Milgram's obedience experiments: A meta-analytic review. Perspectives on Psychological Science, 3(4), 301-304.

Paluck, E. L., \& Green, D. P. (2009). Prejudice reduction: What works? A review and assessment of research and practice. Annual review of psychology, 60, 339-367.

Peery, D., \& Bodenhausen, G. V. (2008). Black+ White= Black: Hypodescent in reflexive categorization of racially ambiguous faces. Psychological Science, 19(10), 973-977.

Pew Research Center (July 10, 2017). Sharp partisan divisions in views of national institutions. Retrieved from: http://www.people-press.org/2017/07/10/sharp-partisan-divisions-inviews-of-national-institutions/

Pewewardy, C. (1996). The Pocahontas paradox: A cautionary tale for educators. Journal of Navajo Education, 14(1-2), 20-25.

Pewewardy, C. D. (1999). From La Belle Sauvage to the Noble Savage: The deculturalization of Indian Mascots in American culture. Multicultural education, 6(3), 6. 
Piff, P. K., Kraus, M. W., \& Keltner, D. (2017). Unpacking the Inequality Paradox: The Psychological Roots of Inequality and Social Class.

Pruckner, G. J., \& Sausgruber, R. (2013). Honesty on the streets: A field study on newspaper purchasing. Journal of the European Economic Association, 11(3), 661-679.

Richard, F., Bond, C., \& Stokes-Zoota, J. (2003). One Hundred Years of Social Psychology Quantitatively Described. Review of General Psychology, 7(4), 331-363 DOI: $\underline{10.1037 / 1089-2680.7 .4 .331}$

Richeson, J. A., \& Sommers, S. R. (2016). Toward a social psychology of race and race relations for the twenty-first century. Annual review of psychology, 67, 439-463.

Ryan, S. (February, 2018). Chief protesters and supporters turn out for focal university’s final home basketball game. Chicago Tribune. Retrieved from: https://www.chicagotribune.com/sports/college/ct-spt-chief-illiniwek-protests-illinoispurdue-20180222-story.html

Schultz, W. P., Khazian, A. M., \& Zaleski, A. C. (2008). Using normative social influence to promote conservation among hotel guests. Social influence, 3(1), 4-23.

Shedd, C. (2015). Unequal city: Race, schools, and perceptions of injustice. Russell Sage Foundation.

Smith, E. R. (2012). Attitudes and social cognition: Editorial. Journal of personality and social psychology, 102(1), 1-3.

Tankard, M. E., \& Paluck, E. L. (2016). Norm perception as a vehicle for social change. Social Issues and Policy Review, 10(1), 181-211. 
Tyler, T. R., \& Jackson, J. (2014). Popular legitimacy and the exercise of legal authority: Motivating compliance, cooperation, and engagement. Psychology, public policy, and law, 20(1), 78.

Waldstein, D. (January 28, 2018). Cleveland Indians will abandon Chief Wahoo Logo Next Year. The New York Times. Retrieved from:

https://www.nytimes.com/2018/01/29/sports/baseball/cleveland-indians-chief-wahoo$\underline{\text { logo.html }}$

Walton, G. M., \& Cohen, G. L. (2007). A question of belonging: race, social fit, and achievement. Journal of personality and social psychology, 92(1), 82. 